\title{
AN OPTIMIZATION MODEL FOR THE OPERATION OF A WATER RESOURCE SYSTEM USING QUADRATIC PROGRAMMING
}

\author{
Alcigeimes B. CELESTE ${ }^{1}$, Koichi SUZUKI ${ }^{2}$, and Akihiro KADOTA ${ }^{3}$ \\ ${ }^{1}$ Member of JSCE, Ph.D. Student, Dept. of Civil and Environmental Engineering, Ehime University (3 Bunkyo-cho, \\ Matsuyama, Ehime 790-8577, Japan) \\ ${ }^{2}$ Member of JSCE, Dr. of Eng., Professor, Dept. of Civil and Environmental Engineering, Ehime University (3 \\ Bunkyo-cho, Matsuyama, Ehime 790-8577, Japan) \\ ${ }^{3}$ Member of JSCE, Dr. of Eng., Assistant Professor, Dept. of Civil and Environmental Engineering, Ehime University \\ (3 Bunkyo-cho, Matsuyama, Ehime 790-8577, Japan)
}

\begin{abstract}
A mathematical optimization model was constructed in order to determine the optimal monthly operation of a multipurpose water resource system composed by a single reservoir and a set of wells. The system is responsible for the water supply of Matsuyama City in Ehime Prefecture. The objectives are to find the optimal monthly allocation of water for city supply and irrigation and to maintain the reservoir storage as close as possible to a given target. The model was solved by Quadratic Programming and its characteristics and implementation are presented. Simulations for different conditions are carried out and the results show that optimization models can serve as good supporting tools for the reservoir operators.
\end{abstract}

Key Words: Reservoir operation, optimization, quadratic programming

\section{INTRODUCTION}

In regions where water resources are scarce the ever-increasing demands require a more efficient management and search for evermore elaborated plans for the operation of the systems. Water resource management systems frequently use mathematical optimization models to identify the best set of plans and policies that provide a fair and economical distribution of water ${ }^{1), 2), 3), 4), 5}$. Optimization models are formulated in terms of determining values for a set of decision variables that will optimize (maximize or minimize) an objective function subject to constraints. The objective function and constraints are represented by mathematical expressions as functions of the decision variables. For the solution of optimization models several algorithms are available from the operations research area, which includes linear and nonlinear programming, dynamic programming, simulation, search techniques and others.

In this study, an optimization model is developed for the monthly operation of a multipurpose water resource system located in Ehime Prefecture, Japan. The objective function is chosen to be quadratic and the solution procedure is thus based on Quadratic Programming (QP).

\section{STUDY SYSTEM AND OBJECTIVES}

The study system is responsible for the water supply of Matsuyama City, capital of Ehime Prefecture, which lies on the northern part of the island of Shikoku, the smallest of the four major islands of Japan (Fig. 1). Matsuyama has a mild climate with an average temperature of $15.6{ }^{\circ} \mathrm{C}$ and average annual precipitation of $1,333 \mathrm{~mm}$ (Fig. 2). There is much rain in June and only a little in January and the city receives little snow and few typhoons.

The system is composed by a multipurpose reservoir named Ishite River Dam and a set of 26 wells located around the Shigenobu River as shown in Fig. 1. Ishite River Dam is located approximately $10 \mathrm{~km}$ to the northeast of the center of Matsuyama City. It is a multipurpose ferroconcrete gravity dam which controls the over flow of Ishite River and provides approximately half of the supply of Matsuyama. Besides, the reservoir is used for irrigation of the northern area of the river, which 


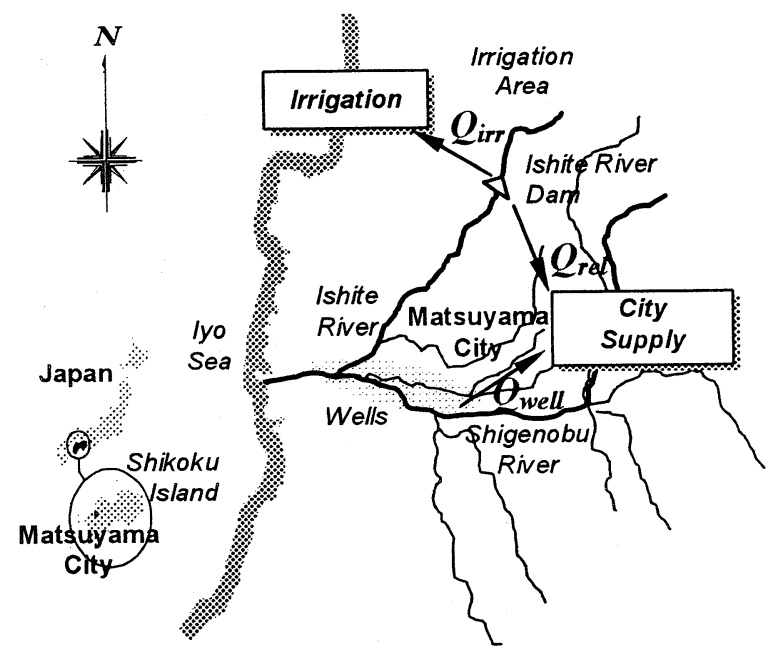

Fig. 1 Location and layout of the system.

extends over the cities of Matsuyama and Hojo and is place for cultivation of tangerine, grape, peach and other citrus fruits. Shigenobu River contains mostly underground water which is used for the other half of the Matsuyama water supply through the set of wells. After the water is taken from the dam and wells, it is transferred to the correspondent surface or underground water treatment plant from where it is distributed to the city. There are two surface and five underground water treatment plants.

The city of Matsuyama suffers periodically with problems originated from the scarcity of water. One example is the current year of 2002, in which there has been a lack of rainfall over the region. Fig. 3 shows the comparison of average rainfall and the measures for 2002 (until beginning of September) at Ishite River Dam, whose water level reached $46.6 \%$ of the capacity in September. Moreover, the population of the city has been increasing substantially and so has the necessity of a better development and management of the water resources in the region.

In the present work, the main objective of the operation is to determine the monthly allocation of water from the reservoir and the set of wells that best satisfy the demands for water supply and irrigation. Another aim is to maintain the reservoir storage as close as possible to a given target storage in order to not let it decrease considerably. Besides, the distribution of water should not compromise the operation of the system violating its constraints and leading it to a collapse.

\section{OPTIMIZATION MODEL}

Since the objective is to make the allocation of water as close as possible to the demands, the objective function of the optimization model can be written by the sum of deviations of releases from

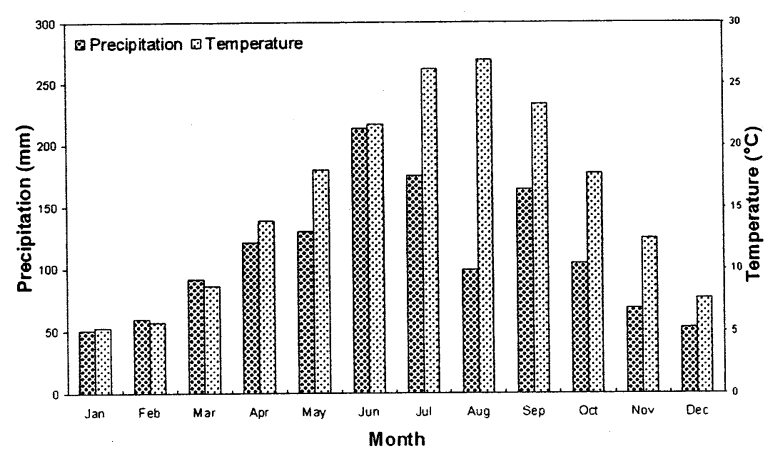

Fig. 2 Average precipitation and temperature in Matsuyama.

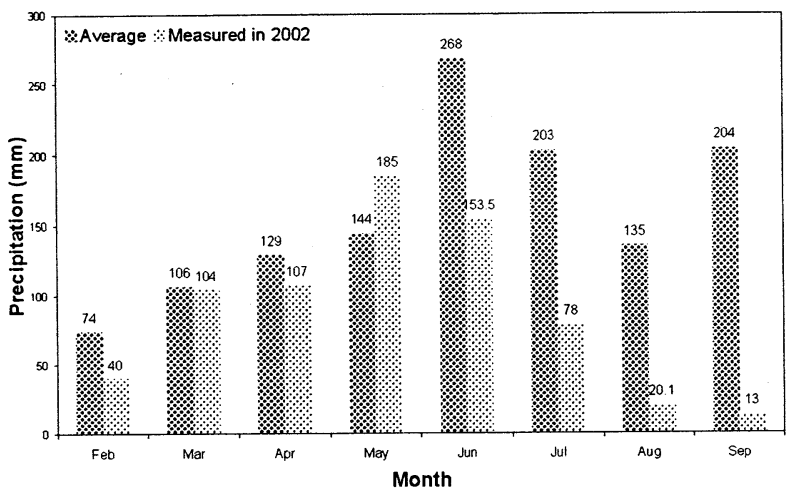

Fig. 3 Average precipitation and measures for 2002 until beginning of September.

their targets. One more term is added to assure that the reservoir storage will not decrease significantly. Constraints are composed by continuity equation, limitations of the components of the system, etc:

$$
\operatorname{minimize} F=\sum_{t=1}^{12}\left\{\begin{array}{l}
\alpha_{1}\left(\frac{Q_{s u p}^{t}-T_{d e m}^{t}}{T_{d e m}^{t}}\right)^{2} \\
+\alpha_{2}\left(\frac{Q_{i r r}^{t}-T_{i r r}^{t}}{T_{i r r}^{t}}\right)^{2} \\
+\alpha_{3}\left(\frac{V_{\text {stor }}^{t}-T_{\text {stor }}}{T_{\text {stor }}}\right)^{2}
\end{array}\right\}
$$

subject to

$$
\begin{gathered}
V_{\text {stor }}^{1}=V_{\text {stor }}^{0}+V_{\text {inf }}^{1}-Q_{r e l}^{1}-Q_{i r r}^{1}-V_{\text {spill }}^{1} ; \\
V_{\text {stor }}^{t+1}=V_{\text {stor }}^{t}+V_{\text {inf }}^{t+1}-Q_{r e l}^{t+1}-Q_{i r r}^{t+1}-V_{\text {spill }}^{t+1} ; \forall t \\
Q_{s u p}^{t}=Q_{r e l}^{t}+Q_{\text {well }}^{t} ; \forall t \\
Q_{\text {sup }}^{t} \leq T_{\text {dem }}^{t} ; \forall t \\
Q_{\text {rel }}^{t} \leq Q_{\text {rel }}^{\max } ; \forall t \\
Q_{\text {well }}^{t} \leq Q_{\text {well }}^{\max } ; \forall t \\
Q_{\text {well }}^{t} \leq Q_{\text {well_AVAILABLE }}^{t} ; \forall t
\end{gathered}
$$




$$
\begin{gathered}
Q_{i r r}^{t} \leq T_{i r r}^{t} ; \forall t \\
Q_{i r r}^{t} \leq Q_{i r r}^{\max } ; \forall t \\
V_{\text {stor }}^{\text {dead }} \leq V_{\text {stor }}^{t} \leq V_{\text {stor }}^{\max } ; \forall t \\
Q_{\text {rel }}^{t} \geq 0 ; Q_{\text {well }}^{t} \geq 0 ; Q_{\text {irr }}^{t} \geq 0 ; \forall t
\end{gathered}
$$

where $t$ is the index of the month; $\alpha_{1}, \alpha_{2}, \alpha_{3}$ are coefficients that measure the relative importance given to each of the reservoir operation purposes; $Q_{\text {sup }}^{t}$ is the total water allocated for city supply from the dam $\left(Q_{\text {rel }}^{t}\right)$ and wells $\left(Q_{\text {well }}^{t}\right)$ in month $t ; T_{d e m}^{t}$ is the demand for city supply in month $t ; Q_{i r r}^{t}$ is the allocation for irrigation in month $t ; T_{i r r}^{t}$ is the demand for irrigation in month $t ; V_{\text {stor }}^{t}$ is the reservoir storage in month $t ; T_{\text {stor }}$ is the target reservoir storage; $V_{\text {stor }}^{0}$ is the initial storage; $V_{\text {inf }}^{t}$ is the inflow to the reservoir in month $t ; V_{\text {spill }}^{t}$ is the amount of water that might spill from the weir in month $t ; Q_{r e l}^{\max }$ is the total capacity of the surface water treatment plants; $Q_{\text {well }}^{\max }$ is the total capacity of the underground water treatment plants; $Q_{\text {well_AVAILABLE }}^{t}$ is the amount of water available in the wells in month $t ; Q_{i r r}^{\max }$ is the capacity of the irrigation system; $V_{\text {stor }}^{\text {dead }}$ is the dead storage of the reservoir; and $V_{\text {stor }}^{\max }$ is the capacity of the dam.

\section{SOLUTION PROCEDURE}

To solve the optimization problem (1)-(12) a program was implemented in MATLAB environment and solved by one of the procedures that compose the MATLAB Optimization Toolbox ${ }^{6)}$. The selected procedure is able to solve quadratic programming problems of the following form:

$$
\underset{\mathbf{x} \in \mathfrak{R}^{n}}{\operatorname{minimize}} f(\mathbf{x})=\frac{1}{2} \mathbf{x}^{T} H \mathbf{x}+\mathbf{g}^{T} \mathbf{x}
$$

subject to

$$
\begin{cases}A_{i} \cdot \mathbf{x}=\mathbf{b}_{i} & i=1, \ldots, m_{e} \\ A_{i} \cdot \mathbf{x} \leq \mathbf{b}_{i} & i=m_{e}+1, \ldots, m\end{cases}
$$

where $H$ and $A$ are matrices, and $\mathbf{g}, \mathbf{b}$, and $\mathbf{x}$ are vectors. $A_{i}$ refers to the $i$-th row of the $m$-by- $n$ matrix A.

The solution method uses an active set strategy, similar to that described by Gill et al. ${ }^{7)}$, which finds an initial feasible solution by first solving a linear programming problem. An active set $\bar{A}_{k}$ is maintained, which is an estimate of the active constraints (i.e., which are on the constraints boundaries) at the solution point. $\bar{A}_{k}$ is updated at each iteration $k$, and this is used to form a basis for a search direction $\mathbf{d}_{k}$. Equality constraints always remain in the active set $\bar{A}_{k}$. The search direction, $\mathbf{d}_{k}$, is formed from a basis, $Z_{k}$ whose columns are orthogonal to the estimate of the active set $\bar{A}_{k}$ (i.e., $\left.\bar{A}_{k} Z_{k}=0\right)$. Thus, a search direction, which is formed from a linear summation of any combination of the columns of $Z_{k}$, is guaranteed to remain on the boundaries of the active constraints

The matrix $Z_{k}$ is formed from the last $m-l$ columns ( $l$ is the number of active constraints and $l<m$ ) of the QR decomposition of matrix $\bar{A}_{k}^{T}$ :

$$
Q^{T} \bar{A}_{k}^{T}=\left[\begin{array}{c}
R \\
0
\end{array}\right]
$$

A new search direction $\mathbf{d}_{k}$, where $\mathbf{d}_{k}$ is a linear combination of the columns of $Z_{k}\left(\mathbf{d}_{k}=Z_{k} \mathbf{p}\right)$, is sought that minimizes $q(\mathbf{x})$. The vector $\mathbf{p}$ is found by substituting $\mathbf{x}$ for $\mathbf{d}_{k}=Z_{k} \mathbf{p}$ in the quadratic function, as below, and finding its minimum:

$$
f(\mathbf{p})=\frac{1}{2} \mathbf{p}^{T} Z_{k}^{T} H Z_{k} \mathbf{p}+\mathbf{g}^{T} Z_{k} \mathbf{p}
$$

The full description of the procedure is found in the toolbox manual ${ }^{6)}$.

\section{IMPLEMENTATION}

Taking a particular point $\mathbf{w}$, a quadratic function can be written as follows:

$$
\begin{aligned}
f(\mathbf{x}) & =f(\mathbf{w}) \\
& +\frac{1}{2}(\mathbf{x}-\mathbf{w})^{T} H(\mathbf{w})(\mathbf{x}-\mathbf{w}) \\
& +\nabla f^{T}(\mathbf{w})(\mathbf{x}-\mathbf{w})
\end{aligned}
$$

where $H(\mathbf{w})$ and $\nabla f(\mathbf{w})$ are the Hessian matrix and the gradient of function $f$ at point $\mathbf{w}$, respectively. $H(\mathbf{x})$ and $\nabla f(\mathbf{x})$ are defined as below: 


$$
H(\mathbf{x})=\left[\begin{array}{cccc}
\frac{\partial^{2} f(\mathbf{x})}{\partial x_{1}{ }^{2}} & \frac{\partial^{2} f(\mathbf{x})}{\partial x_{1} \partial x_{2}} & \cdots & \frac{\partial^{2} f(\mathbf{x})}{\partial x_{1} \partial x_{N}} \\
\frac{\partial^{2} f(\mathbf{x})}{\partial x_{2} \partial x_{1}} & \frac{\partial^{2} f(\mathbf{x})}{\partial x_{2}{ }^{2}} & \cdots & \frac{\partial^{2} f(\mathbf{x})}{\partial x_{2} \partial x_{N}} \\
\vdots & \vdots & \ddots & \vdots \\
\frac{\partial^{2} f(\mathbf{x})}{\partial x_{N} \partial x_{1}} & \frac{\partial^{2} f(\mathbf{x})}{\partial x_{N} \partial x_{2}} & \cdots & \frac{\partial^{2} f(\mathbf{x})}{\partial x_{N}{ }^{2}}
\end{array}\right]
$$

$$
\nabla f(\mathbf{x})=\left[\begin{array}{c}
\frac{\partial f(\mathbf{x})}{\partial x_{1}} \\
\vdots \\
\frac{\partial f(\mathbf{x})}{\partial x_{N}}
\end{array}\right]
$$

Since $f(\mathbf{w})$ is a constant, minimizing $f(\mathbf{x})$ is the same as minimizing the sum of the second and third elements of the right-hand term of expression (17).

For problem (1)-(12), we have implemented the variables as in Table 1.

Table 1 Implementation of the variables.

\begin{tabular}{|cc|}
\hline Main variables & Auxiliary variables \\
\hline$Q_{\text {sup }}^{1}=x_{1}$ & $Q_{\text {rel }}^{1}=x_{37}$ \\
$\ldots$ & $\ldots$ \\
$Q_{\text {sup }}^{N}=x_{12}$ & $Q_{\text {rel }}^{N}=x_{48}$ \\
$Q_{\text {irr }}^{1}=x_{13}$ & $Q_{\text {well }}^{1}=x_{49}$ \\
$\ldots$ & $\ldots$ \\
$Q_{\text {irr }}^{N}=x_{24}$ & $Q_{\text {well }}^{N}=x_{60}$ \\
$V_{\text {stor }}^{1}=x_{25}$ & $V_{\text {spill }}^{1}=x_{61}$ \\
$\ldots$ & $\ldots$ \\
$V_{\text {stor }}^{N}=x_{36}$ & $V_{\text {spill }}^{N}=x_{72}$ \\
\hline
\end{tabular}

Function $F$ in (1) has thus the following general form:

$$
\begin{aligned}
F(\mathbf{x}) & =\alpha_{1}\left(\frac{x_{1}-T_{\text {dem }}^{1}}{T_{\text {dem }}^{1}}\right)^{2}+\cdots+\alpha_{1}\left(\frac{x_{12}-T_{\text {dem }}^{12}}{T_{\text {dem }}^{12}}\right)^{2} \\
& +\alpha_{2}\left(\frac{x_{13}-T_{\text {irr }}^{1}}{T_{\text {irr }}^{1}}\right)^{2}+\cdots+\alpha_{2}\left(\frac{x_{24}-T_{i r r}^{12}}{T_{\text {irr }}^{12}}\right)^{2} \\
& +\alpha_{3}\left(\frac{x_{25}-T_{\text {stor }}}{T_{\text {stor }}}\right)^{2}+\cdots+\alpha_{3}\left(\frac{x_{36}-T_{\text {stor }}}{T_{\text {stor }}}\right)^{2}
\end{aligned}
$$

Setting all elements of vector $\mathbf{w}$ equal to zero, we find the following Hessian and gradient of function $F$ at w:

$$
\begin{aligned}
& \begin{array}{l}
H(\boldsymbol{w})= \\
{\left[\begin{array}{ccccccccc}
\frac{2 \alpha_{1}}{\left(T_{\text {dem }}^{1}\right)^{2}} & \cdots & 0 & 0 & \cdots & 0 & 0 & \cdots & 0 \\
\vdots & \ddots & \vdots & \vdots & \ddots & \vdots & \vdots & \ddots & \vdots \\
0 & \cdots & \frac{2 \alpha_{1}}{\left(T_{d e m}^{12}\right)^{2}} & 0 & \cdots & 0 & 0 & \cdots & 0 \\
0 & \cdots & 0 & \frac{2 \alpha_{2}}{\left(T_{r r f}^{1}\right)^{2}} & \cdots & 0 & 0 & \cdots & 0 \\
\vdots & \ddots & \vdots & \vdots & \ddots & \vdots & \vdots & \ddots & \vdots \\
0 & \cdots & 0 & 0 & \cdots & \frac{2 \alpha_{2}}{\left(T_{\text {Irr }}^{12}\right)^{2}} & 0 & \cdots & 0 \\
0 & \cdots & 0 & 0 & \cdots & 0 & \frac{2 \alpha_{3}}{\left(T_{\text {stor }}\right)^{2}} & \cdots & 0 \\
\vdots & \ddots & \vdots & \vdots & \ddots & \vdots & \vdots & \vdots \\
0 & \cdots & 0 & 0 & \cdots & 0 & 0 & \cdots & \frac{2 \alpha_{3}}{\left(T_{\text {sor }}\right)^{2}}
\end{array}\right]}
\end{array} \\
& \nabla F(\mathbf{w})=\left[\begin{array}{c}
-\frac{2 \alpha_{1}}{T_{d e m}^{1}} \\
\vdots \\
-\frac{2 \alpha_{1}}{T_{d e m}^{12}} \\
-\frac{2 \alpha_{2}}{T_{i r r}^{1}} \\
\vdots \\
-\frac{2 \alpha_{2}}{T_{i r r}^{12}} \\
-\frac{2 \alpha_{3}}{T_{s t o r}} \\
\vdots \\
-\frac{2 \alpha_{3}}{T_{s t o r}}
\end{array}\right]
\end{aligned}
$$

Thus, problem (1)-(12) was implemented in the MATLAB procedure with the objective function given by $\frac{1}{2} \mathbf{x}^{T} H(\mathbf{w}) \mathbf{x}+\nabla F^{T}(\mathbf{w}) \mathbf{x}$, where $\mathbf{x}$ is as in Table 1 and $H(\mathbf{w})$ and $\nabla F(\mathbf{w})$ are given by (21) and (22), respectively. The constraints (2)-(12) were transformed into matrix $A$ as in (14).

\section{RESULTS AND DISCUSSION}

This section illustrates some results obtained from simulations of the operation of the system by using the optimization model developed.

The data of inflow to the reservoir $\left(V_{i n f}\right)$ and water available in the wells $\left(Q_{\text {well_AVAILABLE }}\right)$ for the year of 1995 were used for the simulations. The target values of demands and reservoir storage were assumed as in Table 2. Table 2 shows the average daily demands for city supply and irrigation. The monthly demands were defined as the sum of the average daily demands for each month. The capacity of the dam was chosen to be up to the flood control level, which means a volume of $8,500,000 \mathrm{~m}^{3}$. The dead storage 


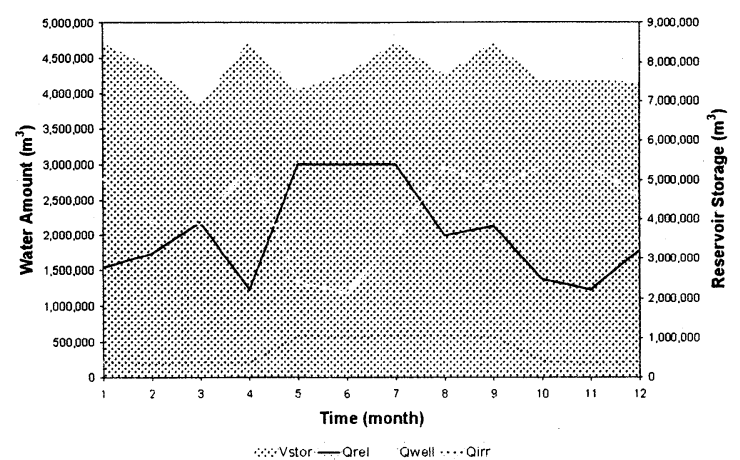

Fig. 3a Optimal storage and allocation (simulation \#1).

Table 2 Target Values of Daily Demands and Reservoir Storage Utilized.

\begin{tabular}{|cc|}
\hline Demands for city supply & $\begin{array}{c}\text { Jul-Sep: } 160,000 \mathrm{~m}^{3} / \text { day } \\
\text { Oct-Jun: } 140,000 \mathrm{~m}^{3} / \text { day }\end{array}$ \\
\hline Demands for irrigation & $\begin{array}{c}\text { May-Sep: } 19,000 \mathrm{~m}^{3} / \text { day } \\
\text { Oct-Apr: } 7,000 \mathrm{~m}^{3} / \text { day }\end{array}$ \\
\hline Target reservoir storage & $7,500,000 \mathrm{~m}^{3}$ \\
\hline
\end{tabular}

of the reservoir is $2,200,000 \mathrm{~m}^{3}$. The initial storage in the dam $\left(V_{\text {stor }}^{0}\right)$ was set as the maximum storage (capacity) for all the simulations.

Fig. 3 shows the results considering the normal inflow for the year of 1995 (named here simulation \#1). Fig. 3a displays the behavior of the reservoir storage and the optimal releases over the year. Fig. $3 \mathrm{~b}$ considers only the results for city supply and shows how much the total allocation from the dam and wells achieve the target demands. Fig. $3 \mathrm{c}$ regards the results for irrigation and also shows how the releases meet the demands. In this operation, priority was given to meeting the demands for city supply and irrigation instead of maintaining the reservoir storage high. This was accomplished by setting $\alpha_{1}=$ $\alpha_{2}=2$ and $\alpha_{3}=1$ in the objective function (1). For this situation of normal inflow all the demands were met appropriately.

Simulations considering a shortage of water were carried out by using the year of 1995 with lower inflows to the dam. For the months of May, June and July only $30 \%$ of the normal inflows were utilized (these months were the ones with higher inflows in 1995). In the other months (January to April and July to December) inflows of $80 \%$ of the normal values were assumed.

Fig. 4 presents the results for the first operation considering the shortage (simulation \#2). For this case, the same priority was given to all the objectives by using $\alpha_{1}=\alpha_{2}=\alpha_{3}=1$. From Fig. $4 \mathrm{~b}$ it is observed that the demands for city supply could not be reached in February, March and June. The demands for irrigation in January were also not met (Fig. 4c).

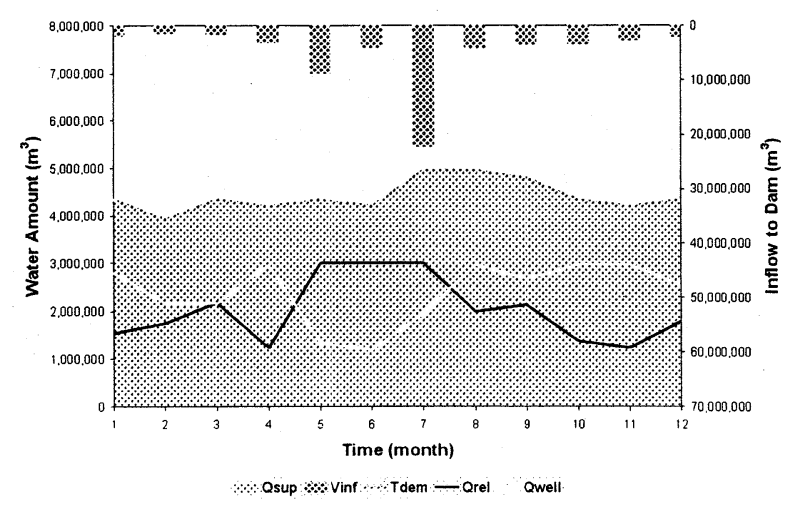

Fig. 3b City supply (simulation \#1).

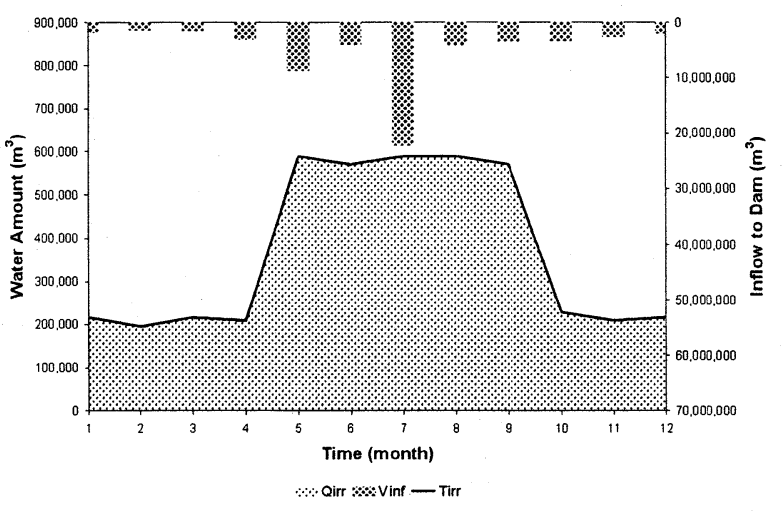

Fig. 3c Irrigation (simulation \#1).

The results from the second operation considering the water shortage are shown in Fig. 5 (simulation $\# 3)$. Now, priority was given to city supply $\left(\alpha_{1}=5\right)$ and irrigation $\left(\alpha_{2}=2\right) . \alpha_{3}$ was kept equal to the unity. Because of that, the demands were met better than in the previous simulation. However, the reservoir storage could not be maintained very close to the target storage.

The above results show how the performance of the system can be analyzed for the same year under various conditions. Reservoir operators can make use of optimization models to do these types of simulations that can serve as screening tools in the decision making process.

\section{CONCLUSIONS}

The analysis of complex water resource systems may involve a high number of decision variables and constraints and optimization models may help in providing operating alternatives which can be used by the water resource planners to assist their decision making.

In this work, an optimization problem based on quadratic programming was applied to the operation of a multipurpose system. The implementation of the objective function as a quadratic function that could be used by a QP procedure was illustrated. 


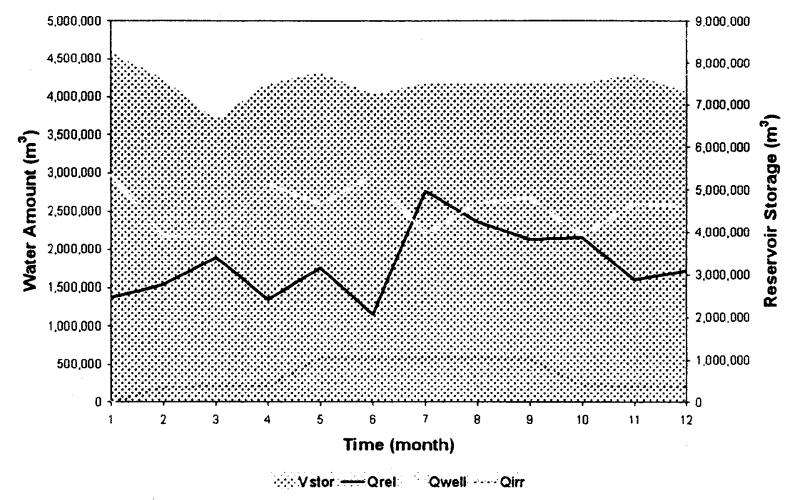

Fig. 4a Optimal storage and allocation (simulation \#2).

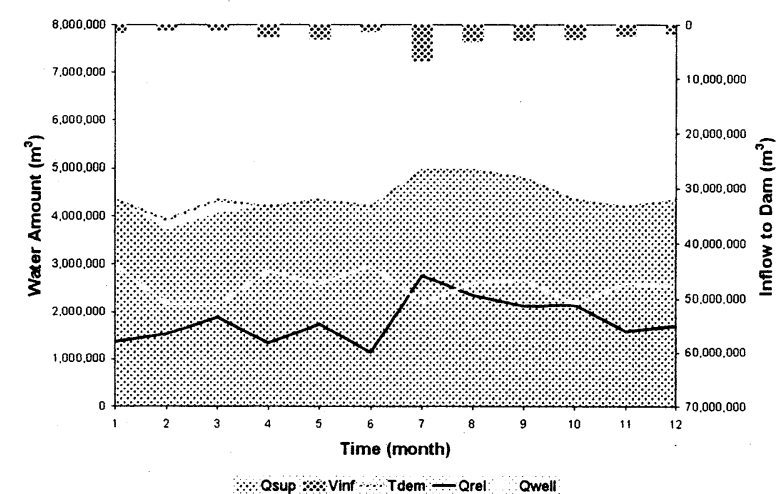

Fig. 4b City supply (simulation \#2).

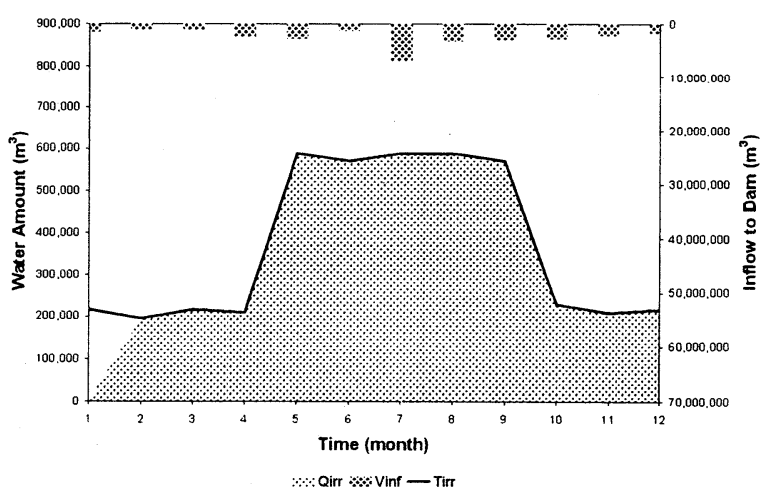

Fig. 4c Irrigation (simulation \#2).

Several simulations were performed with operations for the same horizon (year of 1995) considering different scenarios. The same kind of modeling can be done by the reservoir operators in order to estimate the behavior of the system under different future situations and accordingly decide the best policy to be taken.

\section{REFERENCES}

1) Yeah, W. W-G.: Reservoir management and operations models: a state-of-the-art review, Water Resour. Res., Vol. 21(12), pp. 1797-1818, 1985.

2) Sinha, A. K., Rao, B. V., and Bischof, C. H.: Nonlinear optimization model for screening multipurpose reservoir systems, J. Water Resour. Plng. and Mgmt., Vol. 125(4), pp.

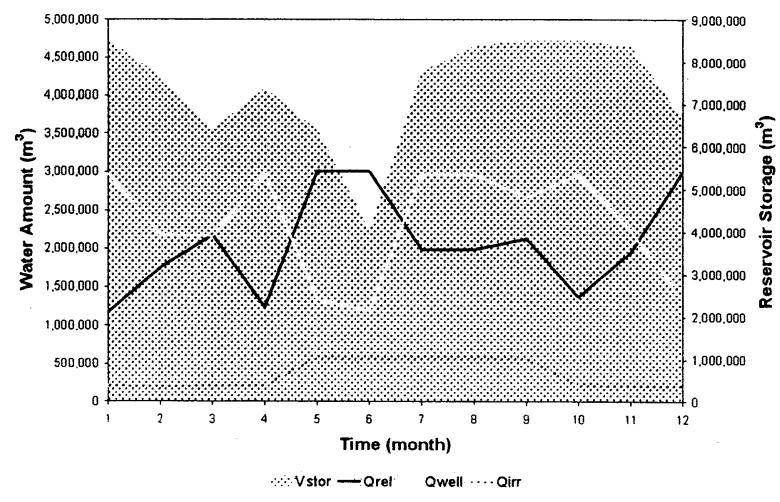

Fig. 5a Optimal storage and allocation (simulation \#3).

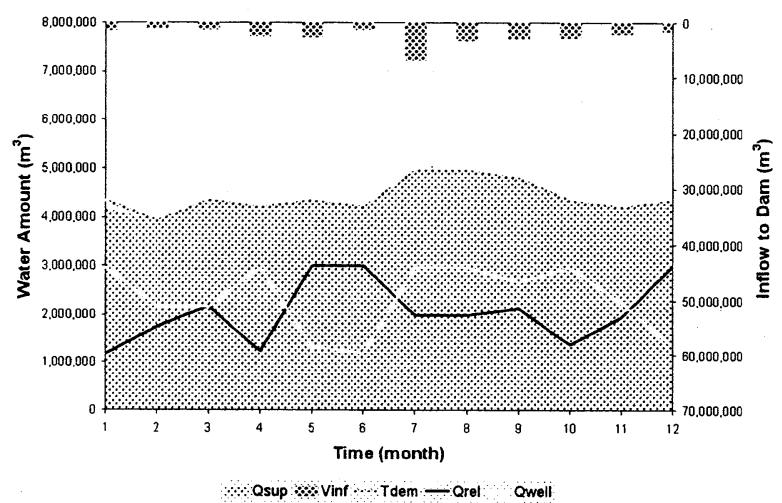

Fig. 5b City supply (simulation \#3).

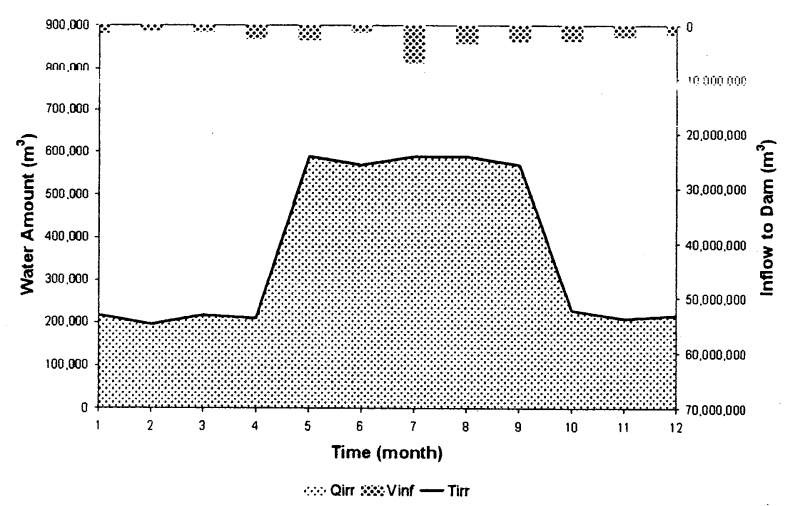

Fig. 5c Irrigation (simulation \#3).

229-233, 1999

3) Belaineh, G., Peralta, R. C., and Hughes T. C.: Simulation/optimization modeling for water resources management, J. Water Resour. Plng. and Mgmt., Vol. 125(3), pp. 154-161, 1999.

4) Houck, M. H.: Real-time daily reservoir operation by mathematical programming, Water Resour. Res., Vol. 18(5), pp. 1345-1351, 1982.

5) Mujumdar, P. P., and Ramesh, T. S. V.: Real-time reservoir operation for irrigation, Water Resour. Res., Vol. 33(5), pp. 1157-1164, 1997.

6) Optimization Toolbox user's guide - version 5, The MathWorks Inc., Natick, Massachusetts, 1996.

7) Gill, P. E., Murray, W., and Wright, M. H.: Practical Optimization, Academic Press, London, 1981.

(Received September 30, 2002) 